\title{
Qatar's Perception of Climate Change and Meeting the Challenges
}

\author{
Ekhlas M. M., Abdel Bary* \\ Environmental Science Center, Qatar University, Qatar
}

Copyright $(2018$ by authors, all rights reserved. Authors agree that this article remains permanently open access under the terms of the Creative Commons Attribution License 4.0 International License

\begin{abstract}
Since the mid-fifties scientists noted a change in the global climate. Previously, reasons for the climate change have been postulated and linked to solar activity and cycles causing events such as cyclical droughts. Climate change was once speculation, an observation, and then backed by scientific evidence and, now, there is no doubt or denial of its impact and real consequences on human lives. It is known that climate change is increasing the incidence, frequency, and magnitude of natural disasters, climate-related hazards, including droughts, fires, powerful typhoons or sea level rise. In the 1990's warming sea temperature related to high temperatures led to coral bleaching which was attributed to El Nino conditions. Climate change disrupts national economies, increases the risk and stress of water, sewer, drainage and transportation systems as well as infrastructure including the risk to human lives. Moreover, there is fear of more drastic effects in the near and far future including solar radiation, volcanoes, etc. More recent observations of a crack in the Antarctic ice caused alarm as what would an increase in sea levels would mean particularly, to lowland countries and islands. The iceberg of Larsen $\mathrm{C}$ has eventually separated off West Antarctica (July 2017). Many have felt recent devastations by hurricanes. It is now accepted that human activities have led to global warming. The majority have now realized that there is a problem and that we have to deal with it. Firstly, we need to take actions to minimize the impact of global warming by finding solutions and taking actions to deal with climate change. The UN led the effort and took action by holding "The Climate Summit" [1] in New York. This undertaking is a partnership between all sectors including farming, range, forest, academia, government, $\mathrm{NGO}$, others to form a serious, legally binding commitment to take effective actions considering mitigation adaptation, and future investments in the energy, biodiversity, sustainability as they relate to climate change. This paper presents the case of Qatar with suggestions for how to deal with climate change and its commitment to the international agenda to reduce greenhouse gas (GHG) emissions.
\end{abstract}

\section{Keywords Qatar, Climate Change}

\section{Introduction}

Climate change is today's most talked about subject at the international and local levels. Governments whether developed or developing discuss the worlds' future and the harmful impact of humans leading directly or indirectly to climate change.

Carbon dioxide emission is considered the main cause of climate change, and it is a fact that the main source of $\mathrm{CO}_{2}$ emission in the atmosphere is from burning fossil fuel. According to EPA [2], the concentration of $\mathrm{CO}_{2}$ has risen from $280 \mathrm{ppm}$ in 1800 to $367 \mathrm{ppm}$ in 1999 . The precision accuracy in the measurement of $\mathrm{CO}_{2}$ have been available since 1957i.e. the Keeling's Curve [3] and using data from "Carbon Dioxide Concentrations in the Atmosphere" is linked to fossil fuel. Based on this, Today's figures are no doubt alarming. According to the World Bank [4], carbon dioxide emissions metric per capita for Qatar was 11.646 in 1955, 99.46 in 1963, 24.714 in 1990, 70.136 in 1997, 37.78 in 2013 and 45.423 in 2014. Such data from industrial countries compelled the world to look into means and ways to combat the rise in $\mathrm{CO}_{2}$ to avert catastrophes.

The solution reached to deal with climate change is a global commitment to actions that will keep the global temperature increase to less than $2.5^{\circ} \mathrm{C}$. The set $1.5^{\circ} \mathrm{C}$ limit is believed to be the safe defense line against the worst impacts of a changing climate. Further, some more actions are to be considered to improve the resiliency of production systems; adapt and mitigate future risks from a changing climate; and further, educate, advocate change knowledge sharing. These actions imply a new sustainable development agenda is a must. It was encouraging that countries; in particular, those with high GHG emissions have adopted the global agreement on climate change. The COP21 Paris [5] lists 17 goals covering poverty, food 
security, health, education, equality (among countries, education and the sexes), water, sanitation, sustainability (energy, economic development, and industrialization) and others. Of the 17 goals, a dozen is required actions directly relating to climate change.

Qatar is a small country with wealth based on fossil fuel. One of the disadvantages of obtaining fossil fuel from its source and processing it is the increase of the Carbon dioxide concentration in the atmosphere, and this bears heavily on a small country's environment.

Qatar is a signature to climate change, Qatar's commitment to national and international treaties is well known, and Qatar does its fair share to a commit to the protection of the environment and sustainable development. The protection of the environment for future generations is spelled out in the Constitution of Qatar [6], and the protection of the environment in the State Law No. 30 and Qatar National Vision 2030 [7, 8] with great stress on Sustainable Development and Food Security. Moreover, Qatar is a signature to all of the seven conservation, environment and protection of biodiversity treaties $[9,10,11,12,13,14$ and 5]. The G20 Summit has confirmed all countries confirmed their commitment except for one [15]. Qatar knows it is highly vulnerable to the adverse effects of climate change and is committed to reducing its carbon dioxide emissions [16].

Urgent global actions were needed, and the prerequisites include; shifting the global economy onto a low-carbon and climate resilient development stance, as well as encouraging a growing global market for energy efficiency and clean energy. Additionally, a search for land-based solutions including new technologies leading to sustainable development growth with an increase in food production to feed a world explodes population. Land-based solutions cover four main goals: food security, economic development, conservation of biodiversity and climate change.

\section{The Case for Qatar}

Qatar is a small country, $185 \times 85 \mathrm{~km}$, situated at $25.3548 \mathrm{~N}, 51.1839$ E. It is semi-surrounded by the Arabian/Persian Gulf and is linked to land at its southern tip to the eastern side of Saudi Arabia by $60 \mathrm{~km}$. Salwa Bay is part of the Gulf, highly saline and with high sea temperatures and separates Qatar from Saudi Arabia and the Kingdom of Bahrain (Figure 1).

Qatar's mainland is flat with -6m below sea level and a maximum of $103 \mathrm{~m}$ above sea level at one point only. Natural water resource is the underground water, which is limited and hardly recharged. Temperature and humidity are high particularly in summer. The mainland is mostly flat land with few outcrops of higher ground and small jebels/tors, and sand dunes at its southern end. Landform also includes wadis, limited depressions, few watercourses and runnels, and a long coastline that is highly saline.
Qatar's mainland is more than $85 \%$ a stony desert built upon limestone rock.

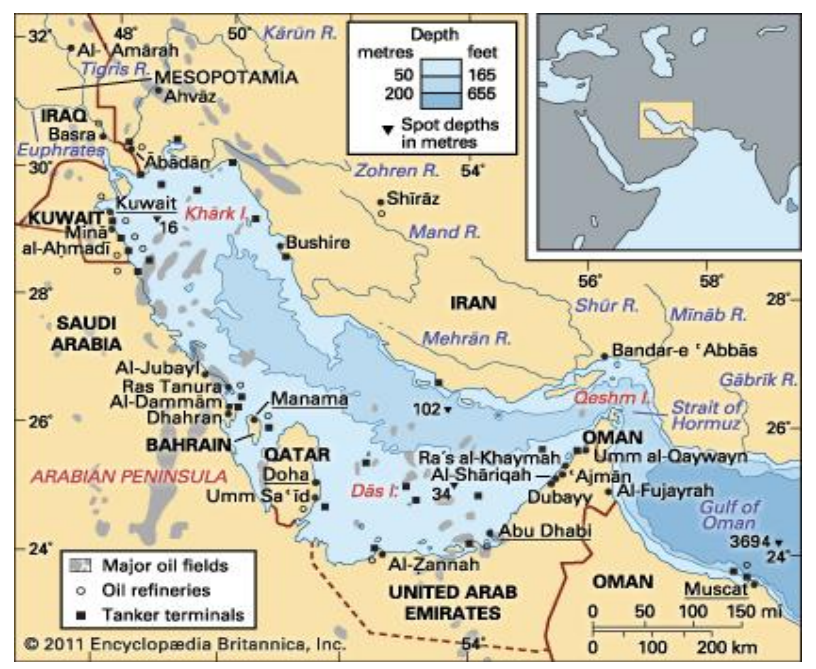

Source: 2011 Encyclopedia Britannica, Inc.

Figure 1. Qatar position in relation to the Arabian Peninsula and the Arabian/Persian Gulf

Qatar is an arid land with scanty and erratic rainfall and temperature varying from cool to extreme heat. Qatar has no natural source of fresh water with no rivers or lakes. Freshwater is from the sea by some desalination plants. Most areas are either barren or with sparse vegetation. The best natural plant cover of limited woody and herbaceous species is in few Rawdat depressions with good loamy soil. There are few agricultural farms mainly in northeastern Qatar investing in the production of fodder, vegetables, poultry and domestic animals.

Qatar has a coastline estimated at more than $700 \mathrm{~km}$ long with different coastal forms and is highly saline. Numerous bays and undulations varying from sandy beaches to rocky shorelines, to eroded low cliffs, to sandy dunes, jetties extending seawards, residential establishment and mangrove forests at the intertidal zone exist.

Qatar has some islands along its coastline. Ras Rakkan, Umm Tais, Umm Al Far, Bu Ghanam, Abu Matar, Al Alyia, Al Safeleya, Al Besheireya, Sheraouh, Ishat and Halul (the only inhabited island and is the main oil transport port) and the artificial islands Al Jazeera, Al Nakheel and Amshat/ Banana are on the eastern coastline.On the western coastline; Al Qa'ud, Yamaz, Umm Feleita and Janan (south of Hewar islands) plus a few unnamed small islands.

\section{Qatar Population and Demands}

Qatar population is now estimated at 2.7 million, mainly living in Doha and its periphery, and in the few main towns such as Al Khor, Al Shamal, Al Wakrah, Al Wekeir, and Umm Bab (where the Cement Factory exists) and in the industrial towns of Mesaieed, Dukhan and Ras Laffan. 
The recent increase in population size of $7.7 \%$ is comparatively rapid. The need of upgrading the infrastructure and preparing for the World Cup 2022 necessitated massive construction and a labor force. The MDPS [17] reports a rapid increase in the labor force. Figure 2 shows the growth rate for 1952-2018.

The local population is a built up of several nationalities. At present, the residents of Qatar include persons from 87 countries. Indians (mainly from Kerala), top the list by 650,000 and the Nepalese come next with more than 350,000 individuals. The Qataris come third with a total of 313,000 [18]. According to the UNDESA [19], the population of Qatar is 2,606,947 individuals. Qataris are mostly of a younger generation with more than $20 \%$ under the age of 15 years.

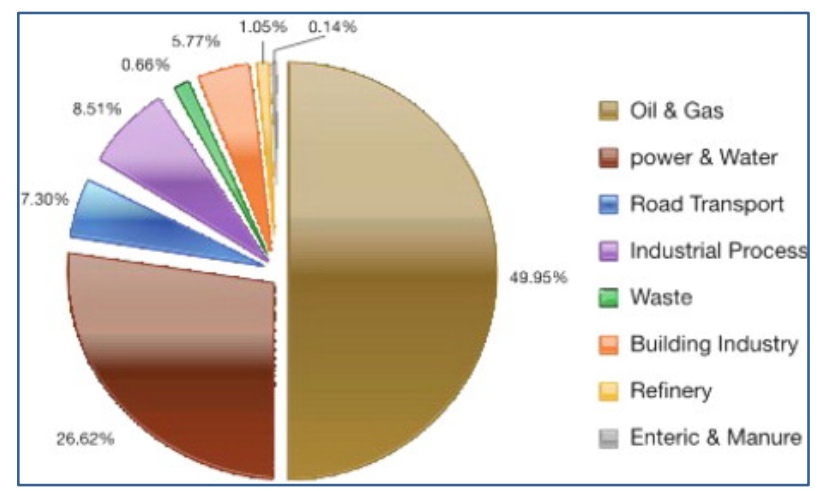

Source: quoted by Alhorr et al. -Initial National Communications (INC). Figure 2. GHG emissions inventory by sectors in Qatar.

The impact of a large population in a non-agricultural country imposes great pressure on demands including the import of food, provision of water, transport, and energy consumption. Larger population requires the consideration of liquid and solid waste disposal, and demands increase in the construction of homes where land is limited. Construction increases dust causing health problems and leads to encroachment on virgin areas causing habitat destruction. Because the country is rich, there is accordingly demand of a certain standard of living that necessitates import of luxury commodities for locals and outsiders to enjoy their wealth and increase in domestic helpers for their comfort.

Qatar is not self-sufficient in needs of agricultural products and imports more than $80 \%$ of its needs of agricultural products. Not surprising, a main concern of Qatar is food security. In recent years, the subject was discussed at many levels and was the main topic in Qatar Vision 2030 [9].

In a recent symposium on Food Security at Doha [20], the main concern was what happens if there is a disruption of supplies from overseas. Qatar has invested in some projects overseas and locally. The recent boycott of Qatar $\left(5^{\text {th }}\right.$ July 2017) by some neighboring countries was not foreseen but confirmed Qatar's concern. Looking at the positive side of events, the increase in local produce and the quality of the products far exceeded all expectations.

\section{Qatar and GHG Emissions}

Qatar is considered as one of the wealthy countries in the World. According to IMF [21], it is the richest country in the world with a $\$ 124.927 .4$ per capita of an estimated 2.27 million. The source of this wealth is from Natural Gas, and Qatar has the third highest reserve of Natural Gas in the world second to Russia and Iran. The source of this revenue is in Qatar's marine zone, and the main petrochemical industries are in three coastal cities; MIC (Mesaieed Industrial City), the first established followed by Dukhan City on the western coastline. RLC (Ras Laffan Industrial City), last established, on the northeastern is the largest and most advanced. Halul Island is an offshore port about $90 \mathrm{~km} \mathrm{NE}$ of Doha and is the main oil exporting port.

Since 1970, gas production and industrialization are on the increase. Due to this and dust storms, air quality is poor and with impact on human health. There is no denial that Qatar is high in carbon dioxide emissions. Per capita, Qatar was listed as the top of a list of other much larger countries [22]. Such placing has been disputed in recent years since now the population is over 2.5 million as compared to the 1.7 million of 2011 and that the calculations were at the time based on 3 out of 4 modules set by the World Bank. Al-Asmakh and Al-Awaini [23] state that this categorizing is unfair arguing that Qatar produces Liquefied Natural Gas (LNG) which is a clean source of energy and it is a producer with the third highest reserve in the world but not a consumer.

Moreover, Qatar has taken important steps to minimize its carbon dioxide emissions by implementing new technologies on the flares in its industrial cities. In 2016, Qatar Steel reported success in reduction of its direct carbon dioxide emission intensity over the years to reach 1 ton of $\mathrm{CO}_{2}$ eq for each ton of steel sold (from 3,753,840 Tons of $\mathrm{CO}_{2}$ in 2014 to $3,567,644$ in 2015 to 3,415,810 in 2016). The International Energy Agency estimates that $7 \%$ of the total world $\mathrm{CO}_{2}$ emissions are associated with the global steel industry. The company also reports a reduction in energy consumption, reduction of sulfur oxide and nitrogen oxide [24]. Further approaches by Qatar to reduce its carbon dioxide emissions, is the aim to design a future building in new cities by 2020 using Global Sustainable Assessment System (GSAS) standards to reduce emissions by at least $30 \%$ [25].

The 2030 Agenda [26] focuses on sustainable development, and the UN with the World Bank have set 2030 as a goal for sustainable energy for all by doubling the global rate of energy efficiency improvement, doubling renewable energy's share in the global energy mix, and ensuring universal access to modern energy services. Qatar's goal should be investing in Clean and 
Safe energy and decreasing dependence on fossil fuel, seeking alternatives such as solar, wind, geothermal and the technologies are available.

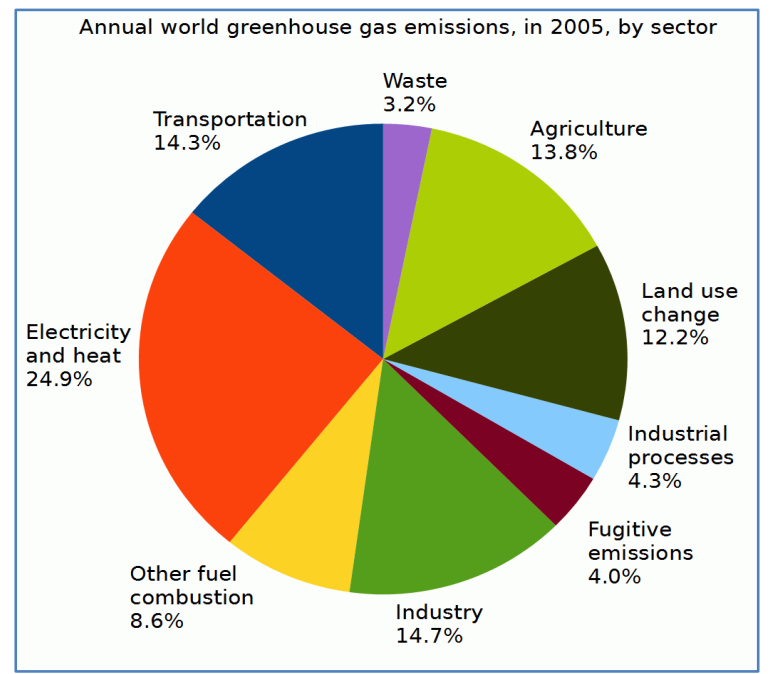

Source: File:Annual world greenhouse gas emissions, in 2005, by sector. $\mathrm{svg}$ /from Wikimedia Commons, the free media repository.

Figure 3a. Main source of GHG emissions

\section{Total U.S. Greenhouse Gas Emissions} by Economic Sector in 2016

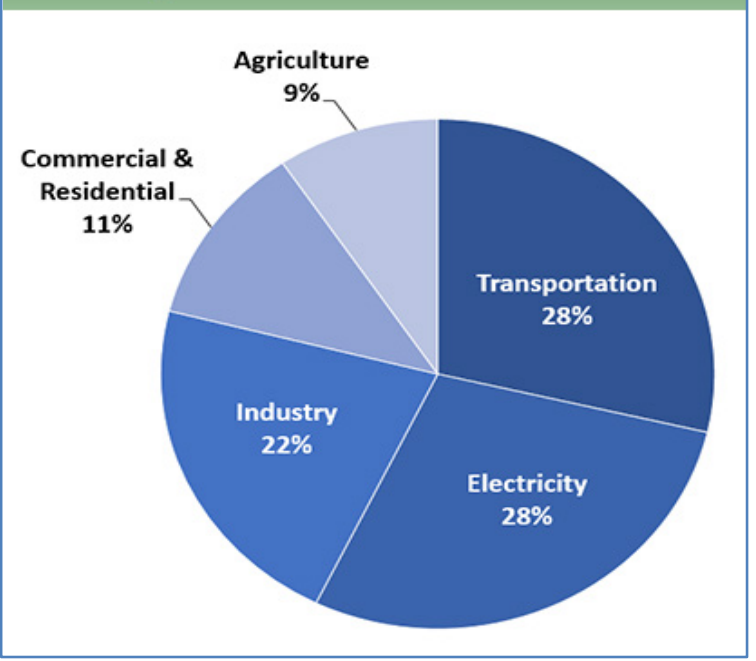

Source: US EPA sources of GHG emissions 2016 (6,511 Million Metric Tons of $\mathrm{CO}_{2}$ equivalent).

Figure 3b. US gas emissions by sector.

Oil production demands a lot of infrastructures involving dredging of the seafloor for pipeline extensions and also the coastal development of industrial cities and their facilities. Dukhan is linked to Mesaieed by an extensive network of pipelines on the mainland. Further, petrol transport to main petrol stations all over the country is by tankers on mainland routes. This situation incurs heavy impact on life in the sea and the land. Gas production for electricity, heat, and industry are responsible for $50 \%$ of GHG emissions and are of four main gasses of which the main component is carbon dioxide. The three main sources of GHG emissions are energy production, industrialization, and transportation and all are the main concern for Qatar. Of the 195 countries who signed the Paris Agreement on mitigation to reduce emissions, 55 are responsible for over $50 \%$ of the global GHG emissions [27]. The Paris Agreement entered into force in 2016. Of these 94 members, equating to $55 \%$ of the total emissions, about 80 percent of the world's energy is supplied through the combustion of fossil fuels, which releases carbon dioxide and other pollutants into the atmosphere (Figure $3 a \quad \& \quad 3 b$ ). Accordingly, all cities are to reduce emissions and become safe, increasingly resilient and sustainable to combat climate change. The main sources of GHG emissions are transportation, electricity, and industry, which are the main concern for Qatar. The agriculture, commercial and residential sectors are of lesser concern at present.

\section{Setting Priority Actions and Facing the Challenges of Their Implementation}

Efforts are needed to face the challenges of the implementation of plans that are directed to global commitment. To understand climate change and acknowledge its impact on human lives, Qatar has to adapt to change since adaptation enables survival and risks have to be identified and mitigated to reduce their impact. Cooperation between the government and the industry is necessary for Qatar to face its challenges and to find land-based solutions such as Smart Agriculture/SfL [28]. The SfL was incorporated in May 2014 as one of the goals of food security, economic development, climate change and conservation of biodiversity. Further, conservation methods are suitable for Qatar, such as for energy and water resources (e.g., the present groundwater use and the impractical agriculture methods in an arid land) are a must. Increasing of plant cover by planting trees using recycled wastewaters would help in reduction of GHG. An introduction of a viable range management system for better animal health consistent with the increase in domestic animals particularly camels that need to free range and the scanty natural vegetation of Qatar should be considered. The protection of seagrass meadows and seaweed beds in the marine zone should be one of the focus tasks for Qatar marine zone. Both are primary producers and contribute to the GHG reduction, possibly more effective than is known and recognized at present.

They are a valuable marine resource that plays a major role as an important food source for marine organisms including the endangered marine turtles, dugong, and some threatened fish species.

Six main goals are of primary importance and are main 
challenges for Qatar:

- Clean and safe energy: Decrease dependence on fossil fuel, depend on alternatives,

- Sustainable economic development:

Development with conservation of biodiversity on land and sea,

- Smart agriculture: Sustainable managed farms and range to meet local food security/marine (seafood and fish are the main food in Qatar), poultry (small land requirement and large protein outcome,

- Increase awareness of water scarcity: Control waste of valuable resources by strict laws (stop the waste of water obtained by numerous desalination plants in unwise domestic use), discourage and forbid the use of the sole natural and valuable groundwater resource (in impractical agricultural methods in an arid land),

- Refine recycling and storage of wastewater: Use ultra-filtration for a refined treatment for recycling and store water in safe, sterile closed tanks to encourage reuse. Invest in recycling waduo water with a (Smart waduo water system to increase plant cover near mosques),

- Increase plant cover to reduce greenhouse gas emissions: Plant trees, green belts, etc. using recycled domestic wastewaters and encourage by law the many newly constructed complexes to include plant cover.

The local media has an important role including; raising awareness of the public to climate change and its impact with programmed broadcasts directed towards sustainability and conservation. The media can play an important role in making the public aware of laws for the conservation and sustainability of rare resources of both the land and sea and advice on the sensible and wise use of water and sustainable fishing. A major role also depends on the education sector to encourage quality research to serve the desired goals that will eventually minimize the impact of climate change. Education and awareness are important in dealing with all hardships.

An important role for the industries is to provide financial support in projects aiming to reduce the impact of climate change. Financial support with collaboration with the ministries of municipality and environment and other relevant bodies and organizations can be effective in the protection of the marine zone, the coastline, and the mangrove forest.

\section{Further Recommended Actions for the Region}

The Gulf encompasses some unique and productive ecosystems. These include sedimentary organisms with valuable ecosystems that include seagrass meadows, seaweed beds coral reefs, sponges and oyster beds. All countries sharing the Gulf must commit to collaborate to meet the goals and objectives in dealing with climate change at the regional level particularly in fossil fuel and marine biodiversity. These efforts must follow the UN and other concerned partners in steps leading to solutions towards global commitments in collaboration to efforts focusing on sustainability and conservation as a task for all those countries that share the blessing of the Gulf irrespective of their political differences. Their motto should be "It is One Sea, and we all depend on it for our survival." These countries must set regulations and policies and abide by them towards Marine protection by programmed hot spots for the Gulf; agreement on the protection of marine biodiversity, particularly of endangered and vulnerable species in their zone with their advancing industrial development; enforcing sustainable fishing and the use of marine resources with sustainability and, limiting coastal development to a minimum. Evidence from seafloor images reveals that some undesired waste is dumped in the sea many of which are non-degradable. Dumping any waste into the sea must be punishable by law, and all countries must set strict rules to preserve the sea. $=$ The deposit of harmful wastes anywhere (marine or terrestrial) damage and impact on the environment and natural resources.

Dredging the seafloor causes turbidity and sedimentation both impacting upon these ecosystems and marine life in general. Moreover, there are some constructed solid jetties along the coastline in a majority of the Gulf coastline strip, which restricts the natural seawater flow and increases sedimentation. Removal of jetties or introducing culverts will allow more flow of seawater, which will reduce the rate of sedimentation that influences sedimentary organisms. A future Smart Jetty design with no obstruction and no sedimentation impact on marine life is recommended for the coastal zone.

Hot Spots for the Gulf are needed to guide conservation policy and recommendations for the marine protected area as a regional choice. Selection of locations should be based on local and regional knowledge. Open ocean hotspots have been defined using data associated with longline fisheries; Census of Marine Life is intended to address such gaps. Applying knowledge of any available data on species richness, diversity, rarity, possible threats (endangered) is advisable where there is pressure on fisheries. Most countries of the Gulf have a fish based diet as their main protein source.

\section{Role of Private Sectors in Food Production}

Worldwide climate disruption to agricultural has been well known and documented to be on the rise for the past 40 years and, predicted to continue to increase for the next 
25 years. It is now apparent that there is no alternative for Qatar except to adopt a chosen solution from Smart Agriculture ideas to enhance food productivity with a focus on Fisheries. A small nation almost surrounded by sea should seek its food source from the sea rather than from the mainland with no surface water resource and poor soil for agricultural purpose. Smart Agriculture must also focus on educating the farmers.

Agricultural Extension was in some countries very popular for the expert and the layman. These focus on programs that are important for introducing methods aiming towards best methodologies and what to grow and when to carry out field actions such as planting, weeding, mulching, fertilizer application, others, in the food and fodder production with a focus on the adaptations to climate change. For Qatar, 2018 is a year of success in agricultural produce. Some companies backed by the government were successful in the production of high production of high-quality produce (meat, poultry, and vegetables). The extremely hot summer, when the temperature exceeds 50 degrees centigrade, makes it difficult to maintain vegetable production during the summer. It is expected that by 2019, Qatar will cover 50\% of its local needs for agricultural products.

\section{Challenge for Qatar in Smart Transportation}

Transportation in all its many aspects (aviation, road, rail, maritime, public transport, vehicles, and fuel and from industries) is responsible for GHG emissions, air pollution (health problems in breathing and the premature deaths (estimated at 3.5 million), life lost annually due to road accidents and others. Already in 2009, transport (vehicles, fuel and transportation infrastructure) contributed approximately to one-quarter of energy-related global GHG emissions and was responsible for about one-fifth of energy use. The UN expert panel's specific actions include the promotion of sustainable transport technologies. Sustainable transport is essential to efforts of dealing with climate change, reducing air pollution (healthcare), leading to fuel savings (lower operational costs), decreasing traffic congestion (delays and stress) and improving road safety.

Qatar in recent years promoted public transport (Bus services of high quality for schools, companies and the public) and now the Metro system to decrease congestion is underway. The ultimate plan is to reduce the number of cars on the road. There is a need for more cooperation and Qatar to establish a monitoring and evaluation of air quality system to advice public on air quality such as dust and pollen counts for health purposes. Qatar must encourage locals and residents to rely on the public transport, and an urgent plan with the great challenge is how to reduce the number of vehicles per household. The number of vehicles in Qatar has been on the rise since 1985 (a record of 127,188 vehicles). For 2015, a total of $1,092,806$ and for 2016, a total of 1,319,563 motor vehicles were registered [29]. Figure 4 shows the gradual increase in vehicles numbers since 2005. The MDPS reported 5443 registered new vehicle for May 2018.

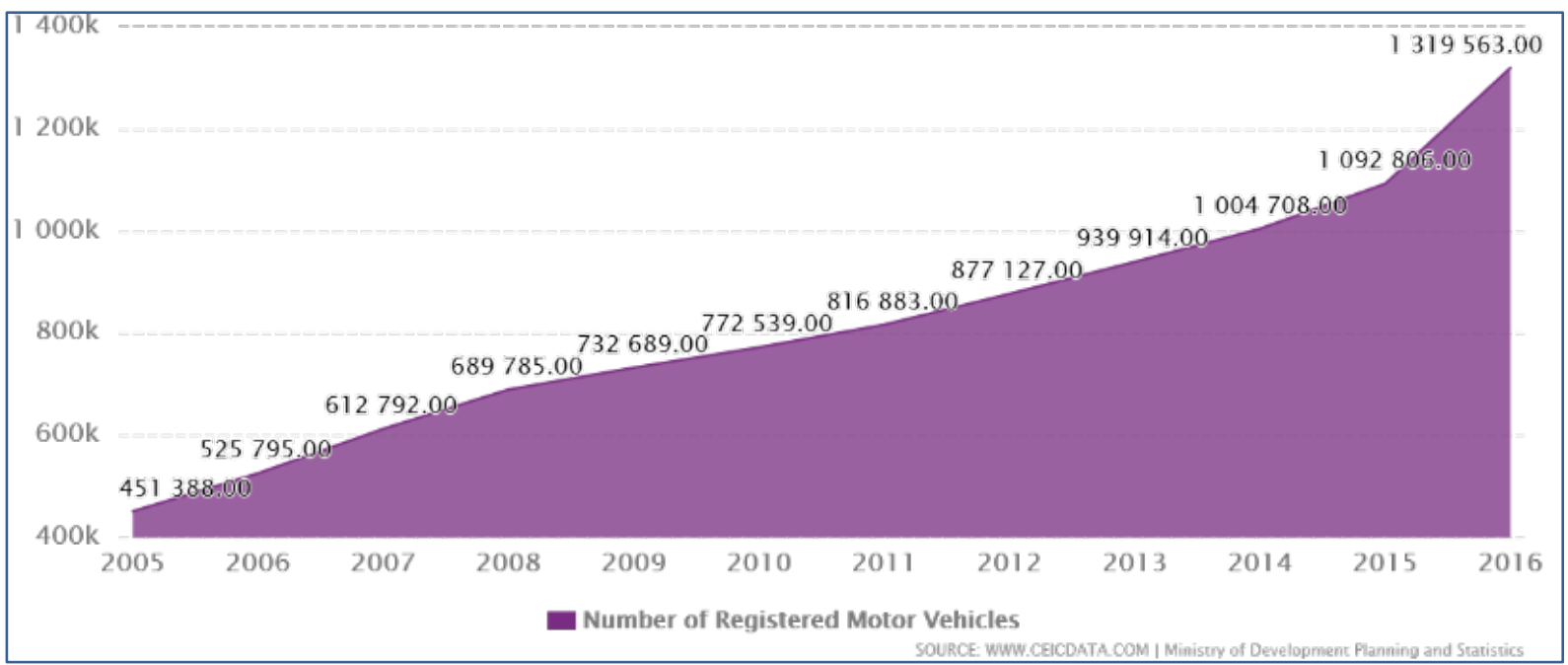

Source: www.ceicdata.com. MDPS 2016.

Figure 4. Number of registered motor vehicles. 
Air quality is poor. The annual average air pollution in Qatar exceeds the WHO and the UN Environment Publication Agency. Besides, air pollution as a byproduct of extensive recent constructions, dust storms, etc. result in a large sector of the population suffering from asthma and allergies. An estimate of $20 \%$ of children between the ages of 8-14 (school age) is asthmatic. Asthma is linked to environmental factors and is in part genetic. Air quality in Qatar is poor due to an increase in dust particles (PM 10) as a byproduct of increased construction activities in buildings and road construction. Equally, poor air quality is due to exposure to pollutant gases from the industry $\left(\mathrm{SO}_{2}, \mathrm{NO}_{2}, \mathrm{O}_{3}\right.$ /ozone depletion substances, $\left.\mathrm{CO}\right)$, heavy air traffic of jet engines, a high number of motor vehicles and at home from house dust, dust mites and Bakhour (Arab incense).Health care is of very high standards in Qatar and the local health authorities continuously issue information to the public as to how to cope with asthma. However, asthma cannot be cured, but it can be managed. A major disadvantage of the attacks is curbing the activity and productivity of an individual.

A recent survey on air quality found that more than $60 \%$ was due to dust particles as compared to $5 \%$ carbon (Figure 5).

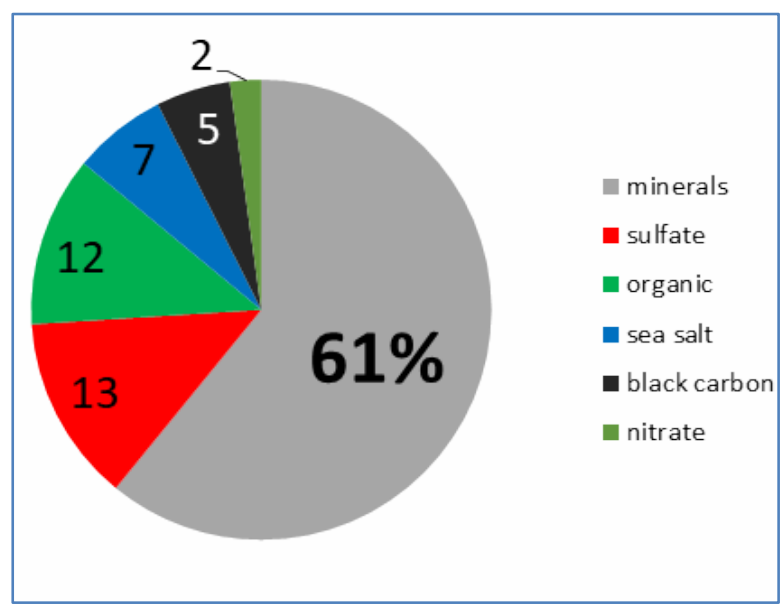

Source: Alfoldy, Balant Zoltan (2017), unpublished data.

Figure 5. Air quality of Doha city.

\section{Conservation of Biodiversity}

Qatar's history, culture, and heritage are linked to marine life. Conservation of Marine biodiversity is a national goal to preserve one's history. The eastern coastline of Qatar is where cultural advancement stemmed and, the site of the original wealth and trade of Qatar. Once a beautiful coastline and shallow intertidal waters with rich biodiversity, now lost to coastal development, solidly constructed jetties leading to sedimentation, continuous dredging of the seafloor leading to loss of the natural marine ecosystems and a site where coastal development continues. This is "a betrayal to one's own culture." The loss of marine biodiversity threatens the food resource for locals and endangered marine species; loss of coastal habitat threatens the loss of coastal vegetation and loss of nesting habitat of the vulnerable Hawksbill marine turtle that nests on the eastern coastline and islands. Qatar is bound by the international agreement to protect the Endangered Species.

Qatar is in urgent need of awakening vision portraying the great loss of local species richness over the recent years and the invasion of foreign/alien species through various channels such as ballast water. Studies are needed to fill the gaps in the information pertaining to species diversity and richness in Qatar marine zone and the terrestrial zone including information on microorganisms. Since 2005, the Environmental Science Center at Qatar University has been involved in analyses of biota in marine sediments and documentation of the seabed and water column by undersea photography from various locations. The rich biodiversity once encountered in the marine sediment samples that amalgamated to our list of over 2,550 species is no more encountered in recently $\%$ collected samples.

\section{REFERENCES}

[1] United Nations Climate Summit. New York, September 2014.

[2] Sources of Greenhouse Gas Emissions. US Environmental Protection Agency (EPA), 1999.

[3] The American Chemical Society (ACS). The Keeling Curve: Carbon Dioxide Measurements at Mauna Loa, May 1, 2015.

[4] The World Bank $\mathrm{CO}_{2}$ emissions (metric tons per capita); GDP per capita Ranking (based on PPP), 2017

[5] COP 21/ Convention United Nations Climate Change Conference Paris, November 2015.

[6] Qatar Constitution. Doha, June 2004.

[7] The Environment Protection Law. State Law No.30 of 2002.

[8] QNV. Qatar National Vision 2030. SENAR 2009.

[9] Convention on Biological Diversity 1992. Rio de Janeiro, June 1992.

[10] CITES 1975. Washington Convention on International Trade in Endangered Species of Wild Fauna \& Flora. July 1975.

[11] CMS. Convention on the Conservation of Migratory Species and Wild Animals. 2004.

[12] PGRFA International Treaty on Plant Genetic Resources for Food and Agriculture. Madrid, 2004.

[13] RAMSAR Convention/Convention on Wetlands. Iran, Feb. 1971. 
[14] Kyoto Protocol to the United Nations Framework Convention on Climate Change. Japan, 1997.

[15] Paris Agreement Status of Ratification UNFCCC. Available online

https://unfccc.int/process/the-paris-agreement/status-of-rat ification

[16] QSDP 2016. Qatar's Commitment to Sustainable Development. Climateactionprogram.org

[17] MDPS labor force survey 2017.The second quarter- AprilJune 2017.Ministry of Development Planning and Statistics, Qatar

[18] Dsouza, Priya 2017. Population of Qatar by nationality. http://priyadsouza.com/population-of-qatar-by-nationalityin-2017/

[19] UN Department of Economics and Social Affairs; Population Division Country meters 2018. Qatar Population. http://countrymeters.info/en/Qatar

[20] Sustainable Development. Achieving Food Security in Arid Environment. Doha, 30, November to $1^{\text {st }}$ December 2016.

[21] IMF, World Economic Outlook Database, January 2018.
[22] Carbon dioxide emissions per capita - www.worldbank.org

[23] Al-Asmakh M. and Al-Awainati 2018. Counting the carbon: Assessing Qatar's carbon dioxide emissions. Qatar Foundation Research Conference Proceedings 2018:EEPD592 http://doi.org/10.5339/qfarc.2018.EEPD592

[24] Qatar steel 2016 https://www.qatarsteel.com.qa/?

[25] Alhorr, Y., Eliskandarani, E., Elsarrag, E. 2014. Approaches to reducing carbon dioxide emissions in the built environment: Low carbon cities. International Journal of Sustainable Built Environment. 3(2): 167-178...

[26] Transforming our world: the 2030 Agenda forSustainable Development, United Nations, 2015.

https://sustainabledevelopment.un.org/post2015/transform ingourworld

[27] UN Climate Change. Article 13 Dec. 2015

[28] The World Bank. Solutions from the land.

[29] Ministry of Development Planning and Statistics. 2016. Qatar number of registered motor vehicles 1985-2016. 